\title{
Pesquisa de enterobactérias em patos domésticos (Cairina moschata) de propriedades localizadas em quatro municípios do Ceará, Brasil
}

\author{
Survey of Enterobacteriaceae in domestic ducks (Cairina moschata) from \\ properties located in four cities of the state of Ceará, Brazil
}

\author{
Emanuella Evangelista da Silva', Elisângela de Souza Lopes' ${ }^{1}$, Régis Siqueira de Castro Teixeira', \\ Átilla Holanda de Albuquerque', Roberta Cristina da Rocha e Silva', Valdez Juval Rocha Gomes Filho', \\ Ruben Horn Vasconcelos ${ }^{1}$, William Cardoso Maciel ${ }^{1 \text { * }}$
}

| | | | | | | | | | | | | | | | | | | | | | | | | | | | | | | | | | | | | | | | | | | | | | | | | | | | | | | | | | | | | | | | | | | | | | | | | | | | | | | | | | | | | | | | | | | | | | | | | | | | | | | | | | | | | | | | | | | | | | | | | | | | | | | | | | | | | | | | | | | | | | | | | | | | | | | | | | | | | | | | | | | | | | | | | | | | | | | | | | | | | | | | | | | | | | | | | | | |

RESUMO: O objetivo deste trabalho foi isolar e identificar as enterobactérias presentes em patos domésticos (Cairina moschata) de propriedades localizadas em quatro municípios no estado do Ceará. Para isso, 47 esfregaços cloacais foram realizados, e 65 amostras de fezes de patos criados em propriedades localizadas nos municípios de Fortaleza, Boa Água, Eusébio e Cascavel foram coletadas. As amostras foram submetidas ao processamento microbiológico. No pré-enriquecimento, todas as amostras de fezes e dos esfregaços cloacais coletados foram alocadas em água peptonada tamponada $0,1 \%$. Para o enriquecimento seletivo, alíquotas da água peptonada com as amostras foram transferidas para tubos contendo Rappaport-Vassilliadis e Selenito-Cistina. Placas de Verde-Brilhante e MacConkey foram semeadas com o conteúdo dos tubos do enriquecimento. Colônias suspeitas escolhidas com base em características morfológicas foram semeadas em provas bioquímicas (TSI: Tríplice Açúcar Ferro; LIA: Ágar Lisina Ferro; e SIM: Sulfeto, Indol, Motilidade). As bactérias foram identificadas com base nas características bioquímicas. Foi detectado, a partir do exame microbiológico, que as enterobactérias mais prevalentes isoladas das amostras de esfregaços cloacais e de fezes foram Citrobacter sp., Proteus sp. e Enterobacter sp. Em menor frequência ocorreram Klebsiella sp., Hafnia sp., Escherichia coli, Shigella sp., Edwardsiella sp., Providencia sp. e Serratia sp. De acordo com a metodologia utilizada, concluiu-se que a microbiota intestinal dos patos avaliados não apresentava Salmonella sp., gênero bacteriano comumente associado a esta espécie de ave; entretanto, observou-se que a fauna microbiana era constituída pelas principais enterobactérias comuns a outras espécies de aves, sendo algumas potencialmente patogênicas aos animais e aos seres humanos.

PALAVRAS-CHAVE: Salmonella; Escherichia coli; aves.
ABSTRACT: This study aimed to isolate and identify members of the Enterobacteriaceae that were present in domestic ducks (Cairina moschata) from properties located in four cities in the State of Ceará, Brazil. Therefore, 65 stool samples and 47 cloacal swabs were collected from farms located in the following cities: Fortaleza, Boa Água, Eusébio and Cascavel. The samples were submitted to bacteriological processing. In pre-enrichment, all of the stool and swab samples were cultured in buffered peptone water $0.1 \%$. For selective enrichment, aliquots from the tubes of the prior step after incubation were transferred to tubes containing Rappaport-Vassiliadis and Selenite Cystine broths. Plates with MacConkey and Brilliant Green agars were streaked with the content from the enrichment tubes after incubation. Colonies were chosen based on their morphological characteristics for the biochemical tests (TSI: Triple-Sugar-Iron; LIA: LysineIron-Agar; and SIM: Sulfide-indole-motility). The bacteria were identified based on their biochemical characteristics. The mostly isolated bacteria were Citrobacter sp., Proteus sp., and Enterobacter sp. In a lower frequency, isolated enterobacteria were Klebsiella sp., Hafnia sp., Escherichia coli, Edwardsiella sp., Providencia sp. and Serratia sp. With the methodology applied, no Salmonella was isolated from the evaluated ducks, which is a genus commonly associated with this avian species; however the microbiota were composed by the main enterobacteria that are common to other species of birds, some of which are potentially pathogenic both to animals and humans.

KEYWORDS: Salmonella; Escherichia coli; birds. 


\section{INTRODUÇÃO}

As bactérias da família Enterobacteriaceae são capazes de se propagar no ambiente desde que sob condições apropriadas, sendo muitas delas consideradas habitantes da flora autóctone intestinal de mamíferos, incluindo o homem, e de algumas espécies de aves (Gerlach, 1994). Segundo Walter et al. (2001), a microbiota intestinal exerce um papel indispensável na manutenção de seu equilíbrio. Essas comunidades microbianas possuem relaçôes simbióticas com o hospedeiro. Como exemplo, a Escherichia coli é considerada um micro-organismo potencialmente patogênico (RosseL, 1992). Porém, existem fatores que causam a alteração da populaçáo de micro-organismos da microbiota intestinal, como jejum alimentar ou hídrico prolongado, estresse, manejo inadequado, variaçôes de temperatura, deficiências na dieta, agentes infecciosos, fatores genéticos e alérgicos, imunodepressão e infecçôes virais (RossKopf; wOERPEL, 1996; GARLICH, 1999), fazendo com que o desequilíbrio microbiano favoreça a fixação de micro-organismos patogênicos (SANTos et al., 2003), o que pode ocasionar o desenvolvimento de enfermidades. As mortes decorrentes de processos infecciosos representam grandes perdas econômicas, principalmente por não existir limite de idade para as infecçôes causadas por enterobactérias (Sathyanarayana et al., 1981).

O local de maior colonização por espécies patogênicas da família Enterobacteriaceae é a mucosa cecal, em comparação a outros locais do trato digestório (ANDreATTI Filho et al., 1997). Assim, o material de predileçâo para verificar a colonização do trato intestinal do animal por enterobactérias são as fezes. Espécies silvestres e animais criados extensivamente nos fundos de quintais, como anatídeos e anserídeos, são carreadores de patógenos entéricos, como Campylobacter sp. e Yersinia sp. (Kapperud; Rosef, 1983; Fukata et al., 1986; Euden, 1990; Aguirre et al., 1991).

No Brasil, assim como em alguns países do noroeste da Ásia, a criação de anseriformes vem aumentando consideravelmente a partir da década de 1980 devido ao aumento significativo do consumo da carne de pato (Cairina moschata) nos últimos anos e ao aumento das populaçóes de gansos (Canada geese) nas metrópoles (Ankey, 1996; Conover, 1985; Conover, 1997). Entretanto, estudos sobre micro-organismos nessas espécies de aves ainda são escassos. Vários autores alertam que as fezes provenientes dessas aves podem conter patógenos que causam doenças em humanos e em animais (Conover, 1985; Conover; Kania, 1991; Fallacara et al., 2001), destacando a importância de estudos microbiológicos para verificar a presença de enterobactérias, de forma a evitar surtos de infecçáo humana e animal. Dessa forma, este trabalho objetivou isolar e identificar as enterobactérias presentes em patos domésticos (Cairina moschata) de propriedades localizadas em quatro municípios do estado do Ceará.

\section{MATERIAL E MÉTODOS}

Para a realizaçáo deste trabalho foram coletadas amostras de fezes $(n=65)$ e de esfregaços cloacais $(n=47)$ de patos domésticos (Cairina moschata) de propriedades localizadas em quatro municípios (Fortaleza, Boa Água, Eusébio e Cascavel) no estado do Ceará. Fezes frescas provenientes dos viveiros foram coletadas com o auxílio de saco plástico e armazenadas sob refrigeraçáo $\left(4^{\circ} \mathrm{C}\right)$ até o processamento microbiológico. O esfregaço cloacal foi realizado individualmente em cada ave com o auxílio de suabe estéril. Após a coleta, as amostras foram transportadas ao Laboratório de Estudos Ornitológicos (LABEO), localizado na Faculdade de Veterinária da Universidade Estadual do Ceará. De cada amostra de fezes, $25 \mathrm{~g}$ foram pesadas e, posteriormente, homogeneizadas em $225 \mathrm{~mL}$ de água peptonada. As amostras oriundas dos esfregaços cloacais foram imersas em $10 \mathrm{~mL}$ de água peptonada. Esse material (suabes e fezes) foi incubado em estufa bacteriológica a uma temperatura de $37^{\circ} \mathrm{C}$ por 24 horas. Após esse período, $0,1 \mathrm{~mL}$ do material incubado foi diluído em $10 \mathrm{~mL}$ de meio Rappaport-Vassilliadis, assim como um mesmo volume $(0,1 \mathrm{~mL})$ também foi diluído em $1 \mathrm{~mL}$ de meio Selenito-Cistina, sendo incubados sob as mesmas temperaturas e pelo mesmo período $\left(37^{\circ} \mathrm{C}\right.$ por 24 horas). Após esse período, as amostras foram plaqueadas em ágar Verde-Brilhante e em ágar MacConkey e foram incubadas por 24 horas a $37^{\circ} \mathrm{C}$. Após obter uma combinaçấo dos meios utilizados nas etapas (quatro placas por amostra), colônias das placas suspeitas para enterobactérias foram entâo escolhidas com base em características morfológicas. Tais colônias foram semeadas em provas bioquímicas, sendo utilizados nesta etapa os meios TSI (meio gelose inclinado Tríplice Açúcar Ferro), LIA (meio gelose inclinado Lisina Ferro) e SIM (Sulfeto, Indol, Motilidade). O volume de $0,15 \mathrm{~mL}$ do reagente de Kovacs foi adicionado ao meio SIM para verificar a produção de indol (BRASIL, 2003). Com base nas características bioquímicas registradas, as bactérias foram identificadas presuntivamente quanto aos seus gêneros.

\section{RESULTADOS E DISCUSSÃO}

Nas 112 amostras processadas (65 amostras de fezes e 47 suabes cloacais), foi possível verificar o isolamento de Citrobacter sp., Edwardsiella sp., Enterobacter sp., Escherichia coli, Hafnia sp., Klebsiella sp., Proteus sp., Providencia sp. e Serratia sp., o que se assemelhou aos achados de Aora et al. (1988), que analisaram amostras procedentes de esfregaços cloacais de 152 patos aparentemente saudáveis e obtiveram 76 isolados de Escherichia coli, 24 de Citrobacter sp., 23 de Enterobacter sp., 4 de Proteus sp., 21 de Klebsiella sp., além de 17 isolados de Pseudomonas aeruginosa. Esses achados podem 
ser considerados relevantes porque, como sugerem Hofer; Costa (1972), a presença de bactérias como Klebsiella sp., Citrobacter sp. e Enterobacter sp. pode ser responsável por vários processos patológicos.

Os gêneros bacterianos isolados em comum observados nas amostras de fezes e nos esfregaços cloacais dos patos foram Enterobacter sp., Citrobacter sp., Proteus sp., Klebsiella sp. e E. coli. A presença desses micro-organismos no trato intestinal das aves, apesar de ser parte de sua flora intestinal, não deve ser desconsiderada, porque algumas dessas espécies podem apresentar algum fator de patogenicidade e trazer risco à saúde do animal (Seo et al., 2000). Outro motivo pelo qual se torna importante detectar esses gêneros bacterianos é o fato de que normalmente os patos são animais criados em contato próximo com os seres humanos, e por isso podem atuar como transmissores de enterobactérias patogênicas ao homem. Harrison; Harrison (1986) relataram que bactérias do gênero Enterobacter e Proteus são geralmente de baixa patogenicidade para as aves. Dessa maneira, o grande número de amostras isoladas poderia náo gerar grandes riscos. Entretanto, a situação inversa deve ser compreendida em relação às bactérias do gênero Escherichia, pois apesar de ter sido encontrado em menor número em amostras de esfregaços cloacais e nas fezes, de acordo com Gerlach (1994), este micro-organismo é comumente encontrado em muitas espécies aviárias, podendo ser considerados agentes mais importantes do que as salmonelas. A espécie Escherichia coli pode infectar aves e causar a doença conhecida como colibacilose em animais imunodeprimidos (Chernaki-Leffer et al., 2002). Durante muito tempo, essa bactéria foi considerada como um micro-organismo não patogênico; no entanto, alguns sorogrupos começaram a ser associados a diversas patologias, tanto

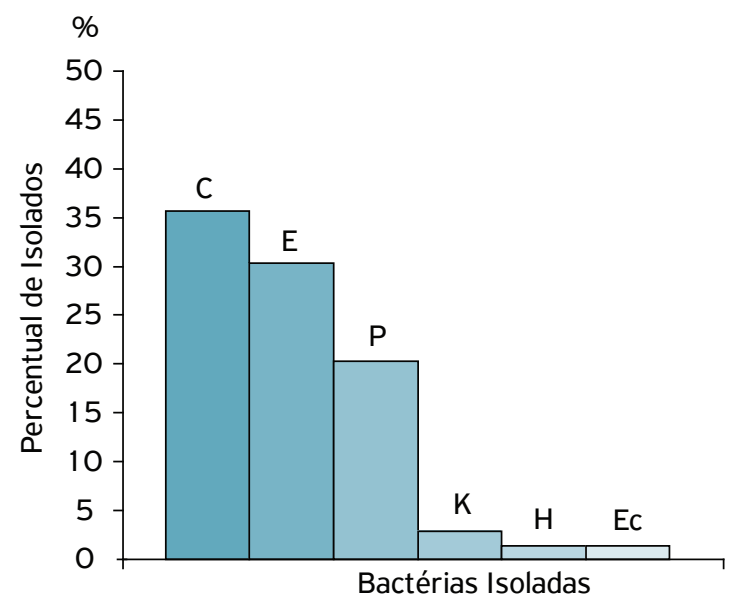

C: Citrobacter sp.; E: Enterobacter sp.; Ec: Escherichia coli; H: Hafnia sp.; K: Klebsiella sp.; P: Proteus sp.

Figura 1. Enterobactérias isoladas de amostras de esfregaços cloacais de patos. no homem quanto nos animais domésticos (Ferreira; KNöBL, 2009). Estudos têm indicado que essa bactéria pode ser facilmente isolada em aves aquáticas de vida livre, principalmente patos (Fallacara et al., 2001).

Entre os micro-organismos menos encontrados nesta pesquisa destaca-se a bactéria do gênero Hafnia, detectada apenas a partir de amostras oriundas de esfregaços cloacais, assim como as bactérias Providencia sp. e Serratia sp. em relaçáo às amostras isoladas a partir das amostras fecais (Figs. 1 e 2). Normalmente, bactérias do gênero Hafnia não têm sido associadas a problemas de saúde em animais ou humanos. Nesse sentido, Günthard; Pennekamp (1996) afirmaram que bactérias do gênero Hafnia ainda não possuem um significado clínico claro. Entretanto, em poedeiras comerciais, Real et al. (1997) descreveram uma septicemia associada à Hafnia alvei. Esses pesquisadores isolaram o micro-organismo de aves que apresentavam baixa produção, perda de apetite, opistótono e mortalidade, além de verificar que esse gênero bacteriano foi capaz de provocar esplenite e hepatite necrosante multifocal.

Comparando os resultados obtidos, percebe-se maior variedade de bactérias isoladas nas amostras de fezes do que nas oriundas dos esfregaços cloacais. Segundo Lima et al. (2001), metade da composição das fezes é constituída de bactérias provenientes do trato intestinal, o que garante maior possibilidade de isolamento.

O maior percentual isolado foi de Proteus sp. nas fezes $(44,76 \%)$ e Citrobacter sp. nos suabes $(38,89 \%)$. O gênero Proteus, isolado em 16 amostras de esfregaços cloacais, obteve a maior representatividade $(35,6 \%)$, considerando os dois tipos de amostras analisadas (suabes e fezes). Este micro-organismo ocasionalmente causa morte embrionária e mortalidade em patos jovens (Venkanagouda; Upadhye, 1996; SAFWAT et al., 1986).

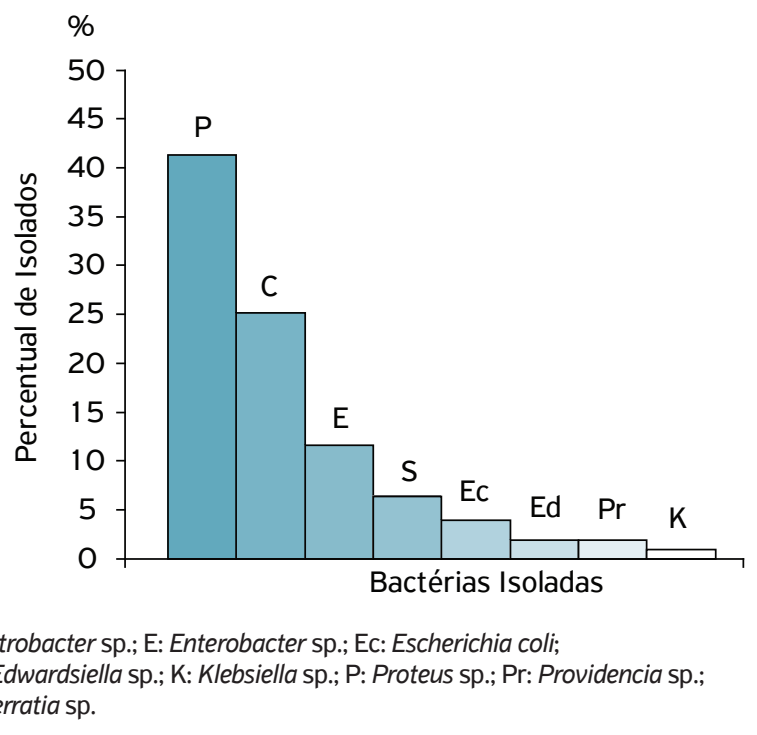

Figura 2. Isolamento de enterobactérias em amostras de fezes de patos. 
Outro micro-organismo que apresentou uma das maiores frequências de isolamento nas amostras de fezes $(32,2 \%)$ foi o gênero Citrobacter. A alta prevalência desta bactéria pode estar associada às condiçóes insatisfatórias de manejo em criaçôes extensivas. São habitantes normais do trato intestinal e respiratório das aves (BARNES, 2003), porém, sob determinadas situaçóes, tornam-se oportunistas e produzem infecçóes em aves jovens, como perus e patos (SEGABinAZI et al., 2005). Ao penetrar na mucosa intestinal, esse gênero bacteriano pode provocar bacteremia e causar a morte de aves jovens (Harrison; Harrison, 1986). Citrobacter sp. pode afetar qualquer espécie de ave e causar mortalidade com ou sem a manifestação de sinais clínicos, tais como um breve período de depressão e diarreia (Gerlach, 1994). Abreu et al. (1999) inocularam experimentalmente Citrobacter diversus, Salmonella Pullorum e Salmonella arizonae em pintos de um dia de vida em duas vias, oral e sacos aéreos. Esses pesquisadores observaram que as lesôes mais marcantes observadas em vários órgãos ocorreram nos grupos inoculados via sacos aéreos, enquanto os pintinhos inoculados via oral apresentaram lesóes menos significativas.

Em 24 amostras de esfregaços cloacais e em 12 amostras de fezes, verificou-se o isolamento de Enterobacter sp., o que representa 20,9\% do total de bactérias isoladas. Este patógeno é um habitante normal do trato digestivo das aves (BINEK et al., 2000), entretanto, em determinadas condições, estas bactérias podem provocar a morte embrionária em ovos férteis e onfalite em aves jovens (BARNEs, 2003).

A bactéria Edwardsiella sp. foi isolada em apenas 1,9\% das amostras de fezes. Resultado semelhante foi obtido por Oliveira et al. (2004), que isolaram 3,3\% de Edwardsiella sp. em amostras fecais de frangos de corte de exploraçóes avícolas industriais. A literatura científica destaca a espécie Edwardsiella tarda como sendo uma bactéria de grande importância em processos patológicos, principalmente em peixes. Apesar disso, mesmo que raramente, aves e seres humanos podem ser acometidos por sérias complicações relacionadas a esse micro-organismo (GARCia et al., 2012; TorRes et al., 2012). Entretanto, nas amostras de patos coletadas neste trabalho não foi identificada a espécie desse gênero bacteriano. Sendo assim, náo se pode afirmar precisamente o significado clínico do micro-organismo isolado.

Náo foi detectada a presença de Salmonella sp. no presente trabalho. A importância desse registro deve-se ao fato de que existe uma vinculação entre a presença dessa bactéria e os patos domésticos, e embora ainda existam poucos estudos sobre esse tema, pesquisas como as de CHA et al. (2013) colocam a Salmonella sp. como um micro-organismo que ocorre comumente em patos. Outros pesquisadores também relataram a importância da Salmonella sp. em patos. Mondal et al. (2008) pesquisaram 65 amostras de esfregaços cloacais de patos provenientes de três regióes diferentes da cidade de Mymensingh (Blangladesh), e verificaram positividade em 9 amostras (13,07\%). RAMPERSAD et al. (2008) encontraram a presença de Salmonella sp. em 110 amostras de fezes que foram coletadas de patos de fundo de quintal de 86 fazendas, localizadas em oito municípios de Trinidad e na ilha de Tobago. Por meio do método microbiológico convencional, eles verificaram positividade em cinco amostras, correspondendo aos sorotipos Kiambu, Orion, Uganda e do grupo E1. Esses pesquisadores também detectaram 44 amostras positivas para Salmonella sp. ao utilizar o teste da reação em cadeia da polimerase (PCR). As infecções por Salmonella sp. são importantes, tanto como causa da doença clínica em patos quanto como fonte de infecção para o homem. Tais infecções podem ser transmitida pelo consumo da carne, sendo, portanto, de grande preocupação sanitária (Mondal et al., 2008). Segundo Gilchrist (1995), o isolamento de Salmonella sp. pode ser dificultado pela provável contaminação das culturas por enterobactérias dos gêneros Citrobacter e Proteus. Além disso, a eliminação de Salmonella sp. não é frequente, dificultando a obtenção de amostras positivas em estudos amostrais de conteúdos internos (Humphrey et al., 1989).

Apesar da ausência de Salmonella sp. observada nessa pesquisa, foi identificada presuntivamente uma variedade de outras enterobactérias de relevante importância. Os patógenos encontrados são considerados micro-organismos oportunistas, e alguns deles fazem parte do grupo dos coliformes, tais como Escherichia coli, Citrobacter sp. e Klebsiella sp. Portanto, a relevância da detecção dessas enterobactérias está no fato de que esses patógenos representam grande importância em termos de saúde pública, uma vez que podem ser transmitidos aos seres humanos por meio do contato direto ou indireto com as fezes de pato domésticos e, com isso, causar infecçóes.

\section{CONCLUSÃO}

De acordo com a metodologia utilizada, concluiu-se que a microbiota intestinal de patos domésticos pertencentes a propriedades localizadas em quatro municípios do estado do Ceará não apresentava Salmonella sp., gênero bacteriano comumente associado a esta espécie de ave. Entretanto, observou-se que a fauna microbiana era constituída pelas principais enterobactérias comuns a outras espécies de aves, sendo algumas delas potencialmente patogênicas aos animais e aos seres humanos. 


\section{REFERÊNCIAS}

ABREU, D.L.C.; SILVA, G.M.; MEDEIROS, M.I.M.; COSTA, C.H.C. Achados patológicos em pintos de 1 dia após inoculação experimental com Salmonella Pullorum, salmonella arizonae e Citrobacter diversus. Revista Brasileira de Ciência Veteterinária, v.6, n.3, p.117-120, 1999.

AGUIRRE, A.A.; COOK, R.S.; MCLEAN, R.G.; QUAN, T.J.; SPRAKER, T.R. Occurrence of potential pathogens in wild Caribbean flamingos (Phoenicopterus ruber ruber) during a lead poisoning die off in Yucatan, Mexico. Journal of Zoo and Wildlife Medicine, v.22, n.4, p.470-475, 1991

ANDREATTI FILHO, R.L.; SILVA, E.N.; CURI, P.R. Ácidos orgânicos e microbiota cecal anaeróbia no controle da infecção experimental de frangos por Salmonella typhimurium e Salmonella enteritidis. Arquivo Brasileiro de Medicina Veterinária e Zootecnia, v.49, n.6, p.661-672, 1997.

ANKEY, C.D. Embarrassment of riches: too many geese. Journal Wildlife Manage, v.60, n.2, p.217-223, 1996.

AORA, A.K.; GUPTA, S.C.; CHAUHAN, R.S.; KAUSHIK, R.K Intestinal carriers of enterobacteria in ducks and their antibiotic and drug resistance spectra. Philippine Journal of Veterinary Medicine, v.25, n. 1, p.23-25, 1988.

BARNES H.J. Miscellaneous and sporadic bacterial infections. In: SAIF Y.M. (Ed.). Diseases of Poultry. 11 ed. Ames: Iowa State. 2003. p.845-862.

BINEK, M.; BORZEMSKA, W.; PISARSKI, R.; BLASZCZAK, B.; KOSOWSKA, G.; MALEC, H.; KARPINSKA, E. Evaluation of the efficacy of feed providing on development of gastrointestinal microflora of newly hatched broiler chickens. Archiv fur Geflugelkunde, v.64, n.4, p.147-151, 2000.

BRASIL. Ministério da Agricultura Pecuária e Abastecimento (MAPA). Instrução Normativa $N^{\circ}$ 62, de 26 agosto de 2003. Métodos analíticos oficiais para análises microbiológicas para controle de produtos de origem animal e água. Disponível em: http://extranet.agricultura.gov.br> Acesso em: 04 maio 2012.

CHA, S.Y.; KANG, M.; YOON, R.H.; PARK, C.K.; MOON, O.K.; JANG, H.K. Prevalence and antimicrobial susceptibility of Salmonella isolates in Pekin ducks from South Korea. Comparative Immunology, Microbiology and Infectious Diseases, v.36, n.5, p.473-479, 2013.

CONOVER, M.R.; CHASKO, G.G. Nuisance Canada geese problems in the eastern United States. Wildlife Society Bulletin, v. 13, n.3 p.228-233, 1985

CONOVER, M.R; KANIA, G.S. Characteristics of feeding sites used by urban-suburban flocks of Canada geese in Connecticut. Wildlife Society Bulletin, v.19, n.1, p.36-38, 1991.

CONOVER, M.R. Wildlife management by metropolitan residents in the United States: practices, perceptions, costs, and values. Wildlife Society Bulletin, v.25, n.2, p.306-311, 1997.
CHERNAKI-LEFFER, A.M.; BIESDORF, S.M.; ALMEIDA, L.M.; LEFFER, E.V.B.; VIGNE, F. Isolamento de Enterobactérias em Alphitobius Diaperinus e na Cama de Aviários no Oeste do Estado do Paraná, Brasil. Revista Brasileira de Ciência Avícola, v.4, n.3, p.243-247, 2002.

EUDEN, P.R. Salmonella isolates from wild animals in Cornwall. British Veterinary Journal, v.146, n.3, p.228232, 1990.

FALLACARA, D.M.; MONAHAN, C.M.; MORISHITA, T.Y.; WACK, R.F. Fecal shedding and antimicrobial susceptibility of selected bacterial pathogens and survey of intestine parasites in free-living waterfowl. Avian Disease, v.45, n.1, p.128-135, 2001.

FERREIRA A.J.P.; KNÖBL, T. Colibacilose. In: BERCHIERI JUNIOR A.; SILVA, E.N.; Di FABIO, J.; SESTI, L.; ZUANAZE, M.A.F. (Ed.). Doença das aves. 2a ed. Campinas: Fundação APINCO de Ciências e tecnologia Avícolas, 2009. p.457-471.

FUKATA, T.; UEMURA, T.; BABA, E.; HORIUCHI, S.; ARAKAWA, A. Isolation of clostridia, salmonellae and coccidia from wild pigeons in Japan. British Veterinary Journal, v.142, n.3, p.291 293, 1986.

GARCIA, N.V.; IREGUI, C.; HIRONO, I. Edwardsiellosis, common and novel manifestations of the disease: A review. Revista Colombiana de Ciencia Animal, v.5, n. 1, p.82-90, 2012.

GARLICH, J.D. Microbiologia do tracto intestinal aviar. In: CONGRESSO LATINOAMERICANO DE AVICULTURA, 16, 1999, Peru. Anais. Lima: Associación Latinoamericana de Avicultura, 1999. p. $110-120$.

GERLACH, H. Bacteria. In: RITCHIE, B.W.; HARRISON, G.J.; HARRISON, L.R. Avian Medicine: Principles and application (Eds.). Wingers Publishing, Inc., Lake Worth, Florida, 1994. p.949-983.

GILCHRIST, M.J.R. Enterobacteriaceae: opportunistic pathogens and other genera. In: MURRAY P.R., BARON E.J., PFALLER M.A., TENOVER F.C.;YOLKEN R.H. (Eds.). Manual of Clinical Microbiology. 6a ed. Washington: ASM, 1995. p.457-464.

GÜNTHARD, H.; PENNEKAMP, A. Clinical significance of extraintestinal Hafnia alvei isolates from 61 patients and review of the literature. Clinical Infectious Diseases, v.22, n.6, p.10401045, 1996.

HARRISON G.J.; HARRISON, L.R (Eds). Clinical Avian Medicine and Surgery. W.B. Saunders Company. Philadelphia. 1986. $717 \mathrm{p}$.

HOFER, E.; COSTA, R.A. Isolamento e identificação de enterobacterias (Apostila). Rio de Janeiro: Instituto Oswaldo Cruz. 1972. 120 p. 
HUMPHREY, T.J.; BASKERVILLE, A.; CHART, H.; ROWE, B. Infection of egg-laying hens with Salmonella enteritidis PT4 by oral inoculation. Veterinary Record, v.125, n.21, p.531522, 1989.

KAPPERUD, G.; ROSEF, O. Avian wildlife reservoir of Campylobacter fetus subsp. jejuni, Yersinia spp. and Salmonella spp. in Norway. Applied and Environmental Microbiology, v.45, n.2, p.375-380, 1983

LIMA, A.O.; SOARES, J.B.; GRECO, J.B (Eds). Métodos de laboratório aplicados à clínica: técnica e interpretação, 8a ed. Rio de Janeiro: Guanabara Koogan. 2001.631 p.

MONDAL, T.; KHAN, M.S.R.; ALAM, M.; PURAKAYASTHA, M.; DAS, M.; SIDDIQUE, M.P. Isolation, identification and characterization of Salmonella from duck. Bangladesh Journal of Veterinary Medicine, v.6, n. 1, p.7-12, 2008.

OLIVEIRA, W.F.; CARDOSO, W.M.; MARQUES, L.C.L.; SALLES, R.P.R.; FILHO, J.L.C.A.; TEIXEIRA, R.S.C.; ROMÃO, J.M.; LIMA, A.C.P. Utilização de diferentes meios de cultura para o isolamento de enterobactérias em amostras fecais de frangos de corte procedentes de explorações industriais do Estado do Ceará, Brasil. Revista Portuguesa de Ciências Veterinárias, v.99. n.552, p.211-214, 2004.

RAMPERSAD, J.; JOHNSON, J.; BROWN, G.; SAMLAL, M.; AMMONS, D. Comparison of polymerase chain reaction and bacterial culture for Salmonella detection in the Muscovy duck in Trinidad and Tobago. Revista Panamericana de Salud Pública, v.23, n.4, p.264-267, 2008.

REAL, F.; FERNANDEZ, A.; ACOSTA, F.; ACOSTA, B.; CASTRO, P.; DÉNIZ, S.; ORÓS, J. Septicemia associated with Hafnia alvei in laying hens. Avian Diseases, v.41, n.3, p.141-747, 1997.

ROSSEL, V. Acidification and probiotics in Spanish pig and calf rearing. In: FULLER, R. Probiotcs: the scientific basis. London: Chapman e Hall, 1992. p.176-180.

ROSSKOPF, W.; WOERPEL, R (Eds). Disease of cage and aviary birds. 3a ed. Baltimore: Williams e Wilkins. 1996. 650p.
SANTOS, M.S.; FERREIRA, C.L.L.F.; GOMES, P.C.; SANTOS, J.L.; POZZA, P.C.; THESSIMA, E. Influência do fornecimento de probiótico à base de Lactobacillus sp. sobre a microbiota intestinal de leitões. Ciência Agrotécnica, v.27, n.6, p.1395-1400, 2003.

SAFWAT, E.E.A.; AWAAD, M.H.; AMMER, A.M.; EL KINAWY, A.A. Studies on Pseudomonas aeruginosa, Proteus vulgaris and $S$. typhimurium infection in ducklings. Egyptian Journal Animal Production, v.24, n.1-2, p.287-294, 1986.

SATHYANARAYANA, R.A.O.M.; RAMACHANDRA, R.N.; ZIAUDINN, S.; RAGHAVAN, R. Colibacillosis in an ostrich (Struthio camelus). Indian Journal of Comparative Microbiology. Immunology and Infectious Diseases, v.2, p.40-41, 1981.

SEGABINAZI, S.D.; FLÔRES, M.L.; BARCELOS, A.S.; JACOBSEN, G.; ELTZ, R.D. Bactérias da família Enterobacteriaceae em Alphitobius diaperinus oriundos de granjas avícolas dos Estados do Rio Grande do Sul e Santa Catarina, Brasil. Acta Scientiae Veterinariae, v.33, n.1, p.51-55, 2005.

SEO, K.H.; HOLT, P.S.; GAST, R.K.; HOFACRE, C.L. Elimination of Early Salmonella enteritidis Infection After Treatment with Competitive-Exclusion Culture and Enrofloxacin in Experimentally Infected Chicks. Poultry Science, v.79, n.10, p. 1408-1413, 2000.

TORRES, A.C.; LOVATO, M.; BRUSTOLIN, J.; CEOLIN, L. V.; HAAS, D. J.; SAGAVE, L.; WEILLER, A. Isolamento de Edwardsiella tarda em galinhas (Galus galus domesticus) necropsiadas no Laboratório Central de Diagnósticos de. Patologias Aviárias. In: CONGRESSO DE INICIAÇÃO CIENTÍFICA, 4a MOSTRA CIENTÍFICA, 21, 2012, Pelotas. Anais, Pelotas: UFPelotas, 2012.

VENKANAGOUDA, G.K.; UPADHYE, A. S. Bacterial etiology of early chick mortality. Indian Veterinary Journal, v.73, p.253-256, 1996.

WALTER, J.; HERTEL, C.; TANNOCK, G.W.; LIS, C.M.; MUNRO, K.; HAMMES, W.P. Detection of Lactobacillus, Pediococcus, Leuconostoc, and Weissella species in human feces by using group-specific PCR primers and denaturing gradient gel electrophoresis. Applied and Environmental Microbiology, v.67, n.6, p.2578-2585, 2001. 